\title{
Role of sirolimus in fibrogenesis inhibition in secondary biliary cirrhosis. Experimental model in
} rat

\begin{abstract}
Background: Chronic hepatopaties are characterized by progression to secondary fibrosis because of extracellular matrix protein deposit (EMP). EMP is produced by myofibroblasts cell type like stellate hepatic cell (SHC) mediated by mammalian target of rapamycin (mTOR), platelet derived growth factor (PDGF), transforming growth factor (TGF- $\beta 1$ ). Sirolimus is an immunosuppressant that inhibits mTOR and is believed to inhibit PDGF and TGF- $\beta 1$.
\end{abstract}

Methods: Double blind randomized controlled assay; control $(\mathrm{n}=10)$ and sirolimus $(\mathrm{n}=10)$. Bile duct ligation (BDL) was done to both groups; biopsies were taken on $28^{\text {th }}$ and $56^{\text {th }}$ postoperative day and blood tests on the $56^{\text {th }}$ day. Sirolimus group was initiated at dose $0.5 /$ $\mathrm{mg} / \mathrm{kg}$ /day. Final biopsies were evaluated for proliferating bile ducts area as a pre-fibrotic marker.

Results: Bilirubin, alanine aminotransferase (ALT) and aspartate aminotransferase (AST) were significant increased in Control Group. Control group showed extensive cholangioles proliferation in Portal space with extension to hepatic lobule.

The proliferating ducts area in Portal space were $1562 \mu \mathrm{m}^{2}$ in Control Group and 208.32 $\mu \mathrm{m}^{2}$ in Sirolimus Group $(\mathrm{p}<0.001)$

Discussion and conclusion: Anti-proliferative effect of Sirolimus was demonstrated in the pre-fibrotic phase in a secondary biliary cirrhosis model in rat. The role of Sirolimus as antifibrogenic therapy in patients with biliary cirrhosis is not yet known.
Volume 4 Issue 2 - 2018

\author{
Carlos Florez-Zorrilla,' Rosa A Fernandez- \\ Capistran, ${ }^{2}$ Cesar Lara-Torres ${ }^{3}$ \\ 'Liver Surgery and Transplantation Unit, American British \\ Cowdray Medical Center, Mexico \\ ${ }^{2}$ Department of Transplantation Hepatology,American British \\ Cowdray Medical Center, Mexico \\ ${ }^{3}$ Department of Surgical Pathology, American British Cowdray \\ Medical Center, Mexico
}

Correspondence: Carlos Florez-Zorrilla, Liver Surgery and Transplantation Unit, The American British Cowdray Medical Center, Calle Sur 132 n$^{\circ}$ 108-408 Colonia Las Américas, CP 0I I20, Mexico City, Mexico, Tel +52 55 26I42 I29, Email florezzc@gmail.com

Received: February 12, 2018 | Published: March 05, 2018
Abbreviations: EMP, extracellular matrix protein; m T O R, mammalian Target of Rapamycin; SHC, stellate hepatic cell; PDGF, platelet derived growth factor; TGF- $\beta 1$, transforming growth factor beta 1; BDL, bile duct ligation; ALT, alanine aminotransferase; AST, aspartate aminotransferase; CTGF, connective tissue growth factor; $\mathrm{H} \& \mathrm{E}$ : hematoxylin and eosin

\section{Introduction}

Following liver or bile duct injury there is a progression to fibrosis due to extracellular matrix protein deposit (EMP). ${ }^{1}$ EMP is produced by myofibroblasts cells type like stellate hepatic cells (SHC), portal, septal and interphase myofibroblasts. ${ }^{2-4}$ SHC transforms into proliferative fibrogenic and contractile myofibroblasts. An important step for SHC transformation is mammalian target of rapamycin (mTor) activation dependant on P13-K/AK1 which is a kinase that control cellular proliferation through synthesis of proteins. ${ }^{5}$

One of the most studied cells is precisely SHC which it is known to be responsible in the liver fibrosis development. ${ }^{5}$ The most potent mitogen for SHC activation is the platelet derived growth factor (PDGF). ${ }^{6}$ This factor is secreted in an autocrine way by SHC but also by cholangioles during cholestasis. The transforming growth factor (TGF- $\beta 1$ ) is a strong fibrogenic stimuli for SHC. ${ }^{7,8}$ Blood levels of
TGF- $\beta 1$ are increased in liver fibrosis and regulate SHC activity in an autocrine manner. Another important cytokine involved in fibrogenesis is connective tissue growth factor (CTGF) associated with over expression of messenger RNA(mRNA) type I, III and IV collagen. ${ }^{9}$

One of the most accepted models for the study of fibrosis development is biliary cirrhosis induction secondary to bile duct ligation. ${ }^{10}$ Following bile duct ligation proliferation of cholangioles are predominant source of co CTGF leading to liver fibrosis. ${ }^{10-12}$ Sirolimus (Rapamune ${ }^{\circledR}$, Pfizer Inc., NY, USA) is a macrocyclic antibiotic, immunosuppressant with antiproliferative properties that suppresses immune system by blocking activation of T-cells. ${ }^{13,14}$

\section{Materials and methods}

\section{Animal model}

20 male Wistar rat of 200-250 g were provided by Karl StorzBrimex II Experimental Surgery Center and received professional care in compliance with the institution and National Health Institute guidelines. The experimental study was approved by the Ethics Committee of the American British Cowdray Medical Center. 


\section{Cirrhosis model}

Animals were randomly distributed to two groups; sirolimus group $(n=10)$ and control group $(n=10)$. Both groups underwent midline laparotomy and common bile duct ligation on day 0 . Induction anesthesia was used with isoflurane and maintenance anesthesia with intraperitoneal pentobarbital at dose of $50 \mathrm{mg} / \mathrm{kg}$.

\section{Treatment}

At $28^{\text {th }}$ postoperative day animals were double blinded and randomly assigned to receive either sirolimus or placebo, they were marked and only one person not involved in the study kept the information in an envelope until the final analysis was done. Sirolimus dose was $0.5 \mathrm{mg} / \mathrm{kg}$ once a day.

\section{Biopsies and blood samples}

Wedge biopsies were taken on 28th postoperative day to both groups. On $56^{\text {th }}$ postoperative day liver function tests were done and for final biopsies an anterior lobe hepatectomy was carried out to both groups and sent for histological evaluation.

\section{Histological assessment}

Hematoxylin and eosin (H\&E), Masson trichrome, PAS and reticulin stains were performed to all samples, and generated from formalin fixed paraffin-embedded tissue blocks. H\&E, PAS and Masson's were blinded scored for portal fibrosis, and cholangioles proliferation area at 10x magnification. Reticulin stain scored degree of collagen deposit. Cholangioles proliferation area was calculated with IN Cell Analyzer 2000 equipment (General Electric Healthcare, United Kingdom). Slides were evaluated by two pathologists both from the American British Cowdray Medical Center and intraobserver consistency was confirmed.

\section{Statistical analysis}

For analysis of variables in two groups, paired Student's t-test was used, a P-value of $<0.05$ was considered to indicate statistical significance. Mann-Whitney U was used for inferential statistics to avoid types I and II errors. Analyses were performed using Statistical Analysis System version 9.3 (SAS Institute, Inc., Cary, NC, USA).

\section{Results}

Biopsies taken on $28^{\text {th }}$ postoperative day, prior to administration of Sirolimus showed no fibrosis and no difference between the two groups. Histological evaluation of rat liver specimens treated with common bile duct ligation and placebo in the Control Group showed extensive proliferation of cholangioles into Portal space with extension to hepatic lobule (Figure 1). Sirolimus group showed limited cholangioles proliferation restricted to Portal space with a mean area of $208.32 \mu^{2}$ (range 143-400) while control group was $1562.07 \mu^{2}$ (range 1000-1840.7). Difference in both groups were statistically significant $(\mathrm{P}<0.001)$ (Table 1$)$. Reticulin stain showed markedly increased collagen deposit in Control group compared to Sirolimus group (Figure 2). Mean bilirubin in Sirolimus group was $0.2 \mathrm{mg} / \mathrm{dl}$ (range 0.1-0.4) and in Control group was $1.35 \mathrm{mg} / \mathrm{dl}$ (range 0.8-1.5) considered statistically significant $(\mathrm{P}<0.001)$. Mean AST in Sirolimus group was $97.5 \mathrm{mg} / \mathrm{dl}$ (range 53-131) and in Control group $240 \mathrm{mg} / \mathrm{dl}$ (range 101-290), mean ALT in Sirolimus group was 52mg/dl (range 37-71) while in Control groups was $87.5 \mathrm{mg} / \mathrm{dl}$ (range 74-91), both ALT and AST were significantly lower in Sirolimus group $(\mathrm{P}<0.05)$
(Table $1 \& 2$ ). Other variables like edema, sinusoidal dilatation, and necrosis although not scored were interpreted by pathologists to be markedly increased in Control Group. Sirolimus treatment was associated with fibrosis inhibition expressed with limited proliferation of bile ducts, and this antiproliferative effect was demonstrated in precirrhotic phase in a secondary biliary cirrhosis model in rat.

Table I Histological and analytical variables.

\begin{tabular}{|c|c|c|c|}
\hline & $\begin{array}{l}\text { Sirolimus } \\
\text { group }\end{array}$ & $\begin{array}{l}\text { Control } \\
\text { group }\end{array}$ & "p" value \\
\hline $\begin{array}{l}\text { Proliferating ducts } \\
\text { area }\left(\mu \mathrm{m}^{2}\right)\end{array}$ & $\begin{array}{l}208.32 \pm \\
80.95\end{array}$ & $\begin{array}{l}1562.07 \pm \\
247.49\end{array}$ & $<0.001$ \\
\hline Edema & + & ++ & NA* \\
\hline $\begin{array}{l}\text { Sinusoidal } \\
\text { dilatation }\end{array}$ & + & +++ & $\mathrm{NA}^{*}$ \\
\hline Necrosis & + & ++ & NA* \\
\hline $\begin{array}{l}\text { Total Bilirubin } \\
(\mathrm{mg} / \mathrm{dl})\end{array}$ & $0.20 \pm 0.1$ & $1.35 \pm 0.2$ & $<0.001$ \\
\hline AST (mg/dl) & $97.5 \pm 22.77$ & $240 \pm 58.72$ & $<0.05$ \\
\hline ALT (mg/dl) & $52 \pm 9.70$ & $87.5 \pm 4.88$ & $<0.05$ \\
\hline
\end{tabular}

Table 2 Proliferative ducts area in $\mu \mathrm{m}^{2}$

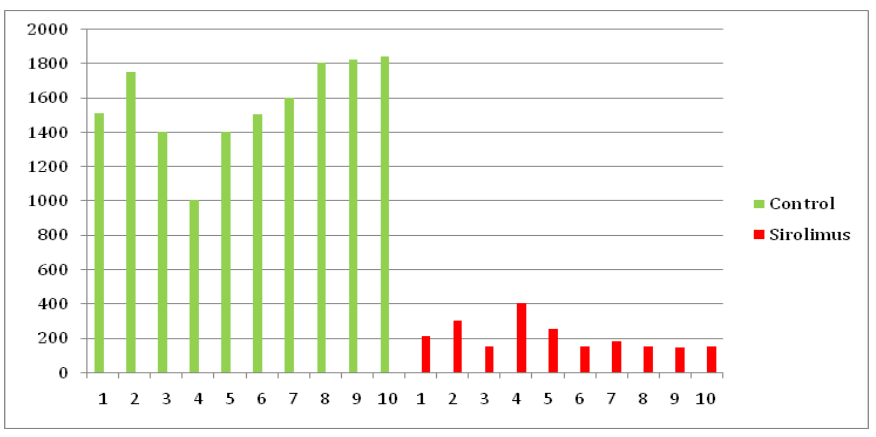

Abbreviations: $\mathrm{ALT}$, alanine aminotransferase;AST,aspartate aminotransferase
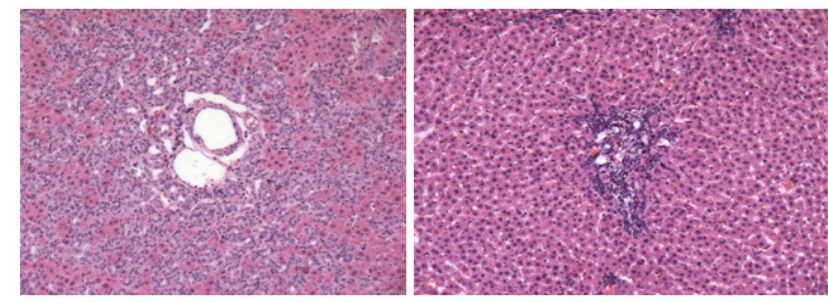

Figure I H \& Ex 10.

I(A) Control group showed extensive proliferation of cholangioles into Portal space with extension to hepatic lobule

I(B) Sirolimus group with mild sinusoidal dilatation and mild proliferation con cholangioles. 


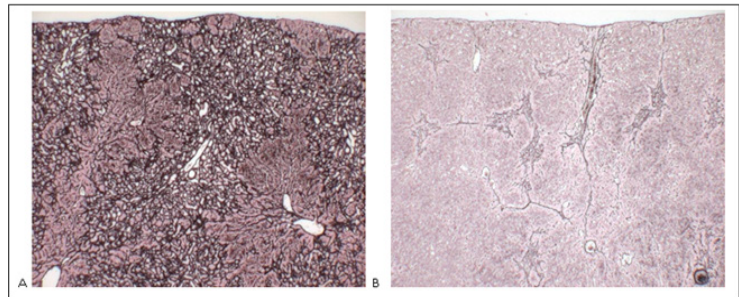

Figure 2 Reticulin 10x.

2(A) Control group showing intense collagen deposit (darker areas)

2(B) Sirolimus group with mild collagen deposit.

\section{Discussion}

Since Zhu et al., ${ }^{15}$ evaluated sirolimus effect on liver fibrogenesis in an experimental model in a secondary biliary cirrhosis induced by long term carbon tetrachloride $\left(\mathrm{CCl}_{4}\right)$ exposure. Sirolimus has multiple effects mainly as an immunosuppressant, but other properties are seen like inhibition of proliferation which interferes with cell cycle. ${ }^{16}$ It is well known that sirolimus binds the FKBP12 protein, and this complex inhibits mTor, a very important step in cellular proliferation. ${ }^{14,15}$

In our study Sirolimus was started immediately after common bile duct ligation, an experimental secondary cirrhosis model described by Zimmermann et al. ${ }^{10}$ Biecker et al. ${ }^{16}$ demonstrated that Sirolimus significantly inhibits liver fibrosis through mTOR cell cycle pathway but also found that in this BDL rats treated with Sirolimus, portal vein pressure, connective tissue, bile duct epithelial cells, actin and desmin positive cells were lower compared to control group. In terms of RNA level, they also found that TGF- $\beta 1$, CTGF and PDGF were decreased by sirolimus treatment. These results correlate well with our findings that cholangioles proliferation is thought to be an important source of collagen and EMP deposit.

We used a low oral dose of Sirolimus $(0.5 / \mathrm{mg} / \mathrm{kg} /$ day $)$ and we demonstrated that this dose has antiproliferative effect and inhibits fibrogenesis. This results were also demonstrated before by Neef et al. ${ }^{17}$ in this study cirrhosis was induced not only by bile duct ligation but also by thioacetamide injections, and they treated rats with Sirolimus once cirrhosis was well established, they found improvement of liver function and prolonged survival benefit, a significant difference with our study because we initiated treatment with Sirolimus in a pre-fibrotic phase, and we don't know if our findings correlates with prolonged survival because it was not the aim of the study, but it seems to be reasonable to investigate further on this matter. Kim et al ${ }^{18}$ also demonstrated in a rat model that TGF- $\beta 1$ and PDGF expression levels in the rapamycin-treated group were lower than those in the untreated group and higher than those in the control groups when using rapamycin at dose of $2 \mathrm{mg} / \mathrm{kg}$.

\section{Conclusion}

In our study sirolimus showed an antiproliferative effect in prefibrotic phase in a secondary biliary cirrhosis model in rat. Sirolimus treatment was associated with limited proliferation of cholangioles. The role of Sirolimus as antifibrogenic therapy in patients with biliary cirrhosis is not yet known.

\section{Acknowledgements}

Dr. Maria del Carmen Hernandez Varo, Director of Karl StorzBrimex II Experimental Surgery Center.

\section{Conflict of interest}

Authors declare that there is no conflict of interest.

\section{References}

1. Friedman SL. Liver fibrosis, from bench to bedside. J Hepatol. 2003;38 Suppl 1:S38-S53.

2. Cassiman D, Roskams T. Beauty is in the eye of the beholder: emerging concepts and pitfalls in hepatic stellate cell research. $J$ Hepatol. 2002;37(4):527-535.

3. Pinzani M, Rombouts K. Liver fibrosis: from the bench to clinical targets. Dig Liver Dis. 2004;36(4):231-242.

4. Knittel T, Kobold D, Saile B, et al. Rat liver myofibroblasts and hepatic stellate cells: different cell populations of the fibroblast lineage with fibrogenic potential. Gastroenterology. 1999;117(5):1205-1221.

5. Friedman SL. The virtuosity of hepatic stellate cells. Gastroenterology. 1999;117(5):1244-1246.

6. Pinzani M, Knauss TC, Pierce GF, et al. Mitogenic signals for plateletderived growth factor isoforms in liver fat-storing cells. Am J Physiol. 1991;260(3 pt 1):C485-C491.

7. Grappone C, Pinzani M, Parola M, et al. Expression of platelet-derived growth factor in newly formed cholangiocytes during experimental biliary fibrosis in rats. J Hepatol. 1999;31(1):100-109.

8. Friedman SL. Cytokines and fibrogenesis. Semin Liver Dis. 1999;19(2):129-140.

9. Frazier K, Williams S, Kothapalli D, et al. Stimulation of fibroblast cell growth, matrix production, and granulation tissue formation by connective tissue growth factor. J Invest Dermatol. 1996;107(3):404-411.

10. Zimmermann H, Blaser H, Zimmermann A, et al. Effect of development on the functional and histological changes induced by bile-duct ligation in the rat. J Hepatol. 1994;20(2):231-239.

11. Van de Casteele M, Sägesser H, Zimmermann H, et al. Characterisation of portal hypertension models by microspheres in anaesthetised rats: a comparison of liver flow. Pharmacol Ther. 2001;90(1):35-43.

12. Sedlaczek N, Jia JD, Bauer M, et al. Proliferating bile duct epithelial cells are a major source of connective tissue growth factor in rat biliary fibrosis. Am J Pathol. 2001;158(4):1239-1244.

13. Wiederrecht GJ, Sabers CJ, Brunn GJ, et al. Mechanism of action of rapamycin: new insights into the regulation of G1-phase progression in eukaryotic cells. Prog Cell Cycle Res. 1995; 1:53-71.

14. Fruman DA, Wood MA, Gjertson CK, et al. FK506 binding protein 12 mediates sensitivity to both FK506 and rapamycin in murine mast cells. Eur J Immunol. 1995;25(2):563-571.

15. Zhu J, Wu J, Frizell E, et al. Rapamycin inhibits hepatic stellate cell proliferation in vitro and limits fibrogenesis in an in vivo model of liver fibrosis. Gastroenterology. 1999;117(5):1198-1204.

16. Biecker E, De Gottardi A, Neef M, et al. Long-term treatment of bile duct-ligated rats with rapamycin (sirolimus) significantly attenuates liver fibrosis: analysis of the underlying mechanisms. J Pharmacol Exp Ther. 2005;313(3):952-961.

17. Neef M, Ledermann M, Saegesser H, et al. Low-dose oral rapamycin treatment reduces fibrogenesis, improves liver function, and prolongs survival in rats with established liver cirrhosis. $J$ Hepatol. 2006;45(6):786-796.

18. Kim YJ, Lee ES, Kim SH, et al. Inhibitory effects of rapamycin on the different stages of hepatic fibrosis. World $J$ Gastroenterol. 2014;20(23):7452-7460. 